\title{
The importance of Li-Fraumeni syndrome, a hereditary cancer predisposition disorder
}

\author{
Belén Miranda Alcalde, M.D. ${ }^{a}$, Marta Villa Alcázar, M.D. ${ }^{a}$, \\ Isabel Martínez Romera, M.D. ${ }^{a}$ and Blanca López Ibor, M.D. ${ }^{a}$
}

\begin{abstract}
Pediatric cancer is rare. It is estimated that more than $10-15 \%$ of tumors are secondary to a pathogenic variant in a cancer predisposition gene.

More than 100 cancer predisposition genes and their association with syndromesorisolated tumors havebeenidentified.Li-Fraumenisyndromeisone of those who have been most widely described. Patients with this syndrome present a high risk of developing one or more tumors. Its knowledge allows to establish a follow-up protocol for the patientand affected family members, soas to detect new tumors in an early manner and reduce tumorand treatment-related morbidity and mortality. The objective of this review is to offer useful guidelines for pediatricians. Based on a family case, reasons for Li-Fraumeni syndrome suspicion, clinical and genetic diagnosis, and the follow-up protocol of family members who carry the same mutation will be reviewed.

Key words: Li-Fraumeni syndrome, hereditary neoplastic syndromes, TP53 gene, neoplasms, pediatrics.

http: / / dx.doi.org/10.5546/ aap.2021.eng.e11
\end{abstract}

To cite: Miranda Alcalde B, Villa Alcázar M, Martínez Romera I, López Ibor B. The importance of Li-Fraumeni syndrome, a hereditary cancer predisposition disorder. Arch Argent Pediatr 2021;119(1):e11-e17.

\section{INTRODUCTION}

The incidence of cancer is low

a. Hospital Universitario HM Montepríncipe, Boadilla del Monte, Madrid, Spain.

E-mail address:

Belén Miranda Alcalde, M.D.:

b.miranda.alc@gmail. com.

Funding:

None.

Conflict of interest: None.

Received: 6-18-2020

Accepted: 7-28-2020 every year, both in Spain and Argentina) and, until a few years ago, it was considered a sporadic condition, which in less than $5 \%$ of cases was related to a genetic disorder. However, with the implementation of new genome sequencing techniques, this figure is constantly increasing, and more than $10-15 \%$ of patients are now estimated to have a pathogenic variant in a cancer predisposition gene.

The genetic predisposition increasing children's risk for developing cancer (cancer predisposition syndrome, CPS) is a reason for concern among parents, pediatricians, and pediatric oncologists. Pediatricians may be the first to suspect a CPS due to a family history of cancer, are involved in the ethical decisions this diagnosis entails, ${ }^{1}$ and are responsible for guaranteeing an adequate follow-up of the patient with CPS and carrier siblings. In addition, CPS diagnosis changes the clinical management of some signs or symptoms that are common in pediatrics (lymphadenopathies, lumps or hematological disorders), ${ }^{2}$ which forces us to consider a tumor in the differential diagnosis.

Pediatric oncologists should contemplate the possibility of their patients having an underlying genetic disorder and must be aware of the natural history and the implications of a CPS when planning treatment and follow-up in order to avoid, as far as possible, radiation in imaging tests and treatment. ${ }^{3}$

Up to the present, many cancer predisposition genes (more than 100) and their association with syndromes or tumors have been identified. One of the most widely described CPSs is LiFraumeni syndrome (LFS).

\section{CASE REPORT: A FAMILY HISTORY}

The family on which this article was based was made up of the parents and three children, who were born in 2007, 2008, and 2010. In November 2008, the eldest child (19 months old at that time), a boy, was taken to consultation with an endocrinologist after having developed pubic hair and acne in the last two months. A precocious puberty test was 
performed, which evidenced hyperandrogenism, and also an abdominal ultrasound, where a right suprarenal mass was detected and then surgically removed, and adrenal adenoma was diagnosed. In the following controls, no residual disease was observed, and treatment was therefore interrupted.

In July 2014, the second sibling, a girl, who was 5 years and 6 months old at the time, was taken to another facility for a consultation on a mass on the left cheek, which was resected. She was diagnosed with alveolar rhabdomyosarcoma. A staging test and a risk group assessment were performed, and stage I was determined, a high-risk group according to the International Society of Paediatric Oncology (SIOP), due to its unfavorable histology. Treatment was planned as per the EpSSG RMS 2005 protocol (subgroup G) and she received chemotherapy and local radiotherapy (45 Gy), which was finished in July 2015. At the time of the second child's diagnosis, it was informed that, in 2009, the father had been diagnosed with leiomyosarcoma of the left upper limb when he was 39 years old and had received treatment.

In August 2014, because of a refractory bilateral conjunctivitis, the eldest child (who was 7 years old at the time) was diagnosed with a heterogeneous intraventricular mass. The tumor was completely removed, and the anatomopathological diagnosis was intraventricular pleomorphic xanthoastrocytoma. The patient did not require chemotherapy or radiotherapy.

In October 2014, genetic testing for LFS was performed in the father (index case) and a heterozygous deletion affecting exons 2-9 of the TP53 gene was confirmed. The test was also performed in the 3 children, and the same mutation was identified in the 2 oldest ones (those previously mentioned), but not in the youngest one.

A LFS follow-up protocol was established for both children, which included an annual whole-body magnetic resonance imaging (MRI) and abdominal and pelvic ultrasound and lab tests every 4 months. In addition, both children continued with the adequate controls for their tumors (rhabdomyosarcoma and intraventricular pleomorphic xanthoastrocytoma, respectively).

In May 2016, while being completely asymptomatic and in remission of her rhabdomyosarcoma, a mass was detected in the second child's posterior cranial fossa in one of the LFS follow-up controls. Surgery was performed and the mass was completely removed, and she was diagnosed with large cell/ anaplastic medulloblastoma with $\mathrm{N}-\mathrm{Myc}(+)$ in the left cerebellum. Adjuvant treatment was planned according to protocol, with radiotherapy and chemotherapy, which ended in July 2017 without residual disease. She was in remission until February 2018, when she presented a recurrence in the cerebellar vermis with cranial vault metastasis. She was treated with secondline chemotherapy and palliative radiotherapy. She died in March 2019. In addition, the father had developed a second tumor (lymphoma) and had died in 2016.

\section{LI-FRAUMENI SYNDROME IN PEDIATRICS}

It has been described that more than $10 \%$ of children with cancer have a genetic disorder that increases their risk for developing malignant tumors. Identifying which patients may have a CPS and knowing how to perform the genetic diagnosis is currently one of the challenges of pediatric oncology. New massive sequencing techniques are opening up new horizons in this field. ${ }^{4}$

In 2016, Jongmans et al. published the criteria that allow to identify patients at "high risk" for cancer genetic susceptibility. ${ }^{5}$ This tool can only be used with pediatric patients already diagnosed with cancer (Table 1).

LFS is a cancer predisposition syndrome which was first described in 1969, when Li and Fraumeni reported the cases of 4 families with 2 or more soft-tissue sarcomas and other neoplasms at a young age. ${ }^{6}$ The TP53 gene has been described to be involved in the pathogenesis of LFS. ${ }^{7}$

LFS is inherited in an autosomal dominant fashion and has a high penetrance. It is characterized by the development of a wide spectrum of tumors, both in childhood and adulthood.

\section{Epidemiology}

The incidence of LFS has been estimated at 1:2000-1:5000 in Europe and North America. However, in certain areas of Brazil, it occurs at a frequency of 1:300 due to the high incidence of a specific $p 53$ mutation. ${ }^{8}$

The mean age at onset of the first tumor in patients with LFS and TP53 mutation is 25 years, with a cumulative risk of $50 \%$ by the age of 30 and above $90 \%$ by age 60 . The risk of developing 
cancer has been estimated at $100 \%$ for women with LFS, whereas for men it is $73 \% .{ }^{9}$ This difference between genders is due to the high incidence of breast cancer among women, which has been described for all age groups. ${ }^{10}$

In addition to being associated with a higher risk for developing different tumors, LFS entails the risk of developing multiple synchronous or metachronous primary tumors. ${ }^{8}$ It has been described that there is a $15 \%$ risk of having second neoplasms, a $4 \%$ risk for third neoplasms, and $2 \%$ risk for four or more. The age at the development of the first tumor has been described to be inversely proportional to the risk of having more than one tumor. Therefore, patients who are diagnosed with their first tumor at ages 0-19 years may have up to an $83 \%$ relative risk of developing a second neoplasm. ${ }^{11}$

\section{Clinical manifestations: cancer descriptions}

LFS patients do not have phenotypic alterations that would help with diagnosis; it will therefore only be guided by family history or the type of tumor. A wide variety of cancers have been detected in the clinical spectrum of LFS; nevertheless, those that have been most commonly described, which are known as "core cancers," account for $70 \%$ of cases and are the following:

- Breast cancer: The most common neoplasm, with a $25-30 \%$ incidence. The mean age of onset is 33 years, and it occurs exclusively in women. ${ }^{12}$
- Sarcomas: They account for $25 \%$ of all cancers. Rhabdomyosarcomas are the most common tumors in pediatric and adolescent patients and their onset is mainly before the age of 5 , whereas osteosarcomas occur at any age. Some of the sarcomas that have not been described in LFS are Ewing sarcomas, gastrointestinal stromal tumors (GISTs), and angiosarcomas, among others. ${ }^{13}$

- Central nervous system (CNS) tumors: They occur in $9-16 \%$ of patients. The most common types are astrocytomas, glioblastomas, medulloblastomas, and choroid plexus carcinomas (CPCs). The mean age of onset is 16 years. Regarding CPCs, they are strongly associated with a TP53 germline mutation, even without a family history of cancer. ${ }^{14}$

- Adrenocortical carcinoma (ACC): It develops in $6-13 \%$ of patients with a bi-modal age distribution (before 5 years of age and between the fourth and fifth decades of life). Its presentation in childhood also suggests a strong association with LFS, and a genetic mutation is detected in $30-80 \%$ of cases, ${ }^{12}$ as revealed in studies on the LFS pediatric population conducted in Brazil.

Other tumors with a much lower incidence, which together account for the remaining $30 \%$ of cases, are leukemia (acute lymphoblastic leukemia [ALL] or acute myeloid leukemia [AML]) and myelodysplastic syndrome (together they represent $2-4 \%$ of cases), gastrointestinal tumors, urogenital cancer, lung cancer, neuroblastoma, and other childhood neoplasms. ${ }^{12}$

TABLE 1. Data for suspicion of cancer predisposition in pediatric cancer patients: modified Jongmans criteria. Adapted from Jongmans et al. Eur J Med Genet. 2016

\begin{tabular}{|c|c|}
\hline Family history data & $\begin{array}{l}2 \text { or more malignancies in family members at } \leq 18 \text { years of age (including the index case). } \\
\text { Parent or sibling with cancer at }<45 \text { years of age. } \\
2 \text { or more first- or second-degree relatives with cancer }<45 \text { years of age on the same side of the family. } \\
\text { The parents of the patient are consanguineous. }\end{array}$ \\
\hline Tumor data & $\begin{array}{l}\text { Diagnosis of a tumor type commonly observed in cancer predisposition syndromes (Table 2). } \\
\text { Detection of an alteration suggesting a germline predisposition in the tumor or biological samples } \\
\text { from the patient. } \\
\text { Patient with } 2 \text { or more malignancies, one of those with onset before } 18 \text { years of age (without } \\
\text { including second tumors consistent in time and / or tissue type with those expected from treatment } \\
\text { regimen). }\end{array}$ \\
\hline Patient data & $\begin{array}{l}\text { Phenotype consistent with cancer predisposition syndrome. } \\
\text { Patient with excessive toxicity to cancer treatment (unexpected toxicity in type, degree or } \\
\text { duration for treatment regimen). }\end{array}$ \\
\hline
\end{tabular}




\section{Clinical diagnosis}

LFS diagnosis is based on the compliance with clinical criteria that identify patients that should be screened for TP53 mutations. In 1988, Frederick P. Li, M.D., and Joseph F. Fraumeni, M.D., described the "classic criteria." Their compliance entails LFS diagnosis, even if it is not genetically confirmed..$^{15}$

In 1990, D. Malkin et al., described the TP53 mutation, which enabled genetic screening to identify individuals with a TP53 mutation who did not meet the classic criteria. For this reason, in the 1990s, the Li-Fraumeni-like syndrome (LFL) was defined in order to identify individuals with broader clinical criteria, who could benefit from genetic studies. ${ }^{7}$ The criteria proposed by Birch et al. ${ }^{16}$ and by Eeles ${ }^{17}$ were then published, and later on those by Chompret, ${ }^{18,19}$ which have been shown to have the highest positive predictive value and higher sensitivity when combined with the classic criteria (Table 2). The TP53 mutation is present in $70 \%$ of patients who meet the classic criteria, $22 \%$ of those who meet Birch criteria, and $20 \%$ of those who meet Chompret criteria.

\section{Genetic diagnosis}

The TP53 gene, located in chromosome 17p13.1, has been described to be involved in the pathogenesis of LFS. In $80 \%$ of cases, the mutation occurs in exons 5-8.

It is a tumor suppressor gene and the most commonly mutated one in tumor cells of all cell lines (its mutation is present in up to $50 \%$ of tumors). The sensitivity of testing methods for genetic disorders ranges from $70 \%$ to $90 \%$ and, when performed through direct sequencing, they reach a $98 \%$ sensitivity. ${ }^{22}$

LFS is characterized by an autosomal dominant inheritance pattern, although de novo mutations have been detected in $7 \%$ of patients. ${ }^{8}$ Its genetic penetrance is very high and an "anticipation" phenomenon is observed in clinical expression within families. ${ }^{23}$

The genotype-phenotype relation explaining the wide variety of LFS clinical presentations is being studied in order to guide patient follow-up towards the cancer types they are most likely to develop. Missense mutations in the DNA-binding

TABLE 2. Clinical criteria for the diagnosis of Li-Fraumeni syndrome

\begin{tabular}{|c|c|}
\hline & Clinical criteria \\
\hline LFS classic criteria ${ }^{20}$ & $\begin{array}{l}\text { Sarcoma diagnosed in a patient younger than } 45 \text { years. } \\
\text { AND } \\
\text { A first-degree relative with any type of cancer, younger than } 45 \text { years. } \\
\text { AND } \\
\text { A first- or second- relative diagnosed with any type of cancer before } 45 \text { years of age or } \\
\text { sarcoma at any age. }\end{array}$ \\
\hline LFL-Birch $^{16}$ & $\begin{array}{l}\text { Pediatric cancer or sarcoma, CNS tumor or ACC diagnosed under } 45 \text { years of age. } \\
\text { AND } \\
\text { First- or second-degree relative with typical LFS cancer (sarcoma, breast cancer, CNS tumor, } \\
\text { ACC, leukemia) diagnosed at any age. } \\
\text { AND } \\
\text { First- or second-degree relative with any cancer diagnosed under age } 60 .\end{array}$ \\
\hline $\begin{array}{l}\text { LFL } \\
\text { Modified Chompret criteria }^{21}\end{array}$ & $\begin{array}{l}\text { Index case with a tumor belonging to the LFS spectrum (sarcoma, breast cancer, CNS tumor, } \\
\text { ACC, leukemia, bronchoalveolar carcinoma) before } 46 \text { years of age. } \\
\text { AND } \\
\text { A first- or second-degree relative with a cancer belonging to the LFS spectrum before } \\
56 \text { years of age (except breast cancer if the index case was affected by breast cancer) or } \\
\text { multiple tumors at any age. } \\
\text { OR } \\
\text { Index case with multiple primary tumors (except multiple breast cancers), at least } 2 \text { of which } \\
\text { belong to the LFS spectrum and the first tumor onset occurs under } 46 \text { years of age. } \\
\text { OR } \\
\text { Index case with ACC or choroid plexus carcinoma or anaplastic rhabdomyosarcoma at } \\
\text { any age, irrespective of the family history. } \\
\text { OR } \\
\text { Breast cancer under } 31 \text { years of age without BRCA1 or BRCA2 mutations. }\end{array}$ \\
\hline
\end{tabular}

LFS: Li-Fraumeni syndrome; LFL: Li-Fraumeni-like syndrome; CNS: central nervous system; ACC: adrenocortical carcinoma. 
domain of the $p 53$ protein have been detected in some cases of breast and CNS cancer, ${ }^{24}$ whereas the p.R337H variant is strongly associated with the development of ACC, according to studies conducted in the pediatric LFS population in Brazil. ${ }^{25}$

Other lines of research are focused on studying "genetic modifiers," i.e. genetic anomalies that may affect the phenotypic expression of a $p 53$ alteration. Some of these modifiers are the MDM2 alteration (direct negative regulator of $p 53$ ) and a shortened telomere length, which are related to tumor development at a younger age. ${ }^{26,27}$ Other genes that may be involved are being studied, such as $C H K 2,{ }^{28}$ in the remaining families with LFS or LFL and no TP53 mutation.

\section{Follow-up of diagnosed patients}

In order to detect tumors in an early manner and reduce morbidity and mortality, multiple follow-up protocols have been developed (Australia Protocol, Toronto Protocol, National Comprehensive Cancer Network). ${ }^{29}$ Several survival studies have been conducted to determine if follow-up protocols are associated with increased life expectancy. ${ }^{19}$ To date, the follow-up group results are favorable: overall survival rates in patients with and without follow-up were $88.8 \%$ and $59.6 \%$ after 5 years, respectively. ${ }^{30}$ These differences are due to the early diagnosis of tumors at an initial stage or premalignant lesions. ${ }^{31}$

Among the different follow-up programs, it is worth noting that developed by the American Association for Cancer Research (AACC) in 2016 (Table 3). The recommendation is initiating follow-up in all patients with a genetic diagnosis of LFS, as well as in those who meet the classic criteria of the syndrome, even without genetic confirmation. ${ }^{31}$

\section{Family study}

A family study is the first problem to be addressed when a family member is diagnosed with LFS, in order to include mutation carriers in the follow-up protocol. All first-degree relatives of the index case should be studied..$^{32,33}$ Genetic counseling is another of the important discussions to be had, given its autosomal dominant inheritance and high penetrance.

\section{COMMENTS ON THE CLINICAL CASE}

Most adrenocortical tumors are sporadic, but some of them develop in association with genetic disorders. The most common ones are LFS, Beckwith-Wiedemann syndrome (BWS), multiple endocrine neoplasia type 1 (MEN1), and familial adenomatous polyposis (FAP).

When the eldest child was diagnosed with adrenocortical adenoma in 2008, its association with a genetic condition was considered, but he had no family history of cancer nor phenotypic features consistent with a genetic disorder. At that time, the patient did not meet Jongmans criteria for CPS suspicion nor classic or Chompret LFS criteria.

Initially, genetic testing was not indicated and, just a year later, his father was diagnosed with sarcoma, but this information was not reported until 2014, when the second child was diagnosed with cheek rhabdomyosarcoma.

If LFS had been diagnosed before, the initial management of the second child would have been different, given that the lesion was treated as a benign tumor and resected at another facility with no prior biopsy nor adequate free margins. When the second child was diagnosed with another sarcoma, the need for ruling out LFS became evident, and screening was done.

It is not possible to determine whether the overall survival of the father or the daughter

TABLE 3. Follow-up recommendations for Li-Fraumeni syndrome in patients younger than 18 years (Kratz CP, et al. Clin Cancer Res; 23(11):e38-e45)

- Physical examination every 3-4 months (including BP, growth curves, Cushingoid appearance, signs of virilization, and full neurologic assessment).

- Ultrasound of abdomen and pelvis every 3-4 months (to particularly rule out ACC).

- Annual brain MRI (first MRI with contrast; thereafter without contrast if not necessary).

- Annual whole-body MRI (to look for soft tissue and bone sarcoma).

- When faced with any relevant symptom, the patient must immediately see their pediatrician/pediatric oncologist or primary care physician.

BP: blood pressure; ACC: adrenocortical carcinoma; MRI: magnetic resonance imaging. 
would have been different, given the high level of aggressiveness of the tumors they both had, but the fact is that LFS diagnosis was delayed from November 2008 to August 2014, and in that period there were three malignant tumors in the family which were not detected due to the lack of follow-up protocol. After LFS diagnosis, the two following tumors (medulloblastoma in the second child and lymphoma in the father) were diagnosed in this context. In addition, diagnostic radiation was avoided in the eldest child.

It is evident that radiotherapy should be avoided in LFS patients, as long as tumor curability is not compromised. Radiotherapy was not necessary in the eldest son; however, it was impossible to avoid it in the case of the second child due to the histological aggressiveness of both tumors.

\section{CONCLUSIONS}

Pediatricians play a critical role in the management of patients with LFS. It will be the patient history collected by the pediatrician that will lead to LFS suspicion. We reaffirm the need for recording the history of cancer among first- and second-degree relatives in the medical records of pediatric patients, and this should be done regularly, since they change significantly from one visit to the next, as we have seen in this clinical case. Tumors in young people (younger than 45 years and, even more, in those younger than 18 years) are particularly relevant. To that end, it is advisable to use family trees and carefully record the type of tumor and the age at onset.

Diagnosing a CPS is as important as avoiding making the family feel they might have a predisposition if that is not the case. In the specific case of LFS, pediatricians should work together with oncologists and geneticists so as to ensure the correct diagnosis of the patient, the study of family members, and an adequate compliance of necessary follow-up protocols among affected relatives. In addition, radiation should be minimized (diagnostic and therapeutic) and recommendations on basic secondary preventive measures should be provided (avoiding sun exposure, tobacco, and alcohol).

\section{REFERENCES}

1. Kumar RK, Ghali M. Li-Fraumeni syndrome-What does it mean for the general practitioner and general paediatrician? Paediatr Child Health. 1998; 3(6):411-2.

2. Teplick A, Kowalski M, Biegel JA, Nichols KE. Educational paper: screening in cancer predisposition syndromes: guidelines for the general pediatrician. Eur J Pediatr. 2011; 170(3):285-94.

3. Gonzalez KD, Noltner KA, Buzin CH, Gu D, et al. Beyond Li Fraumeni Syndrome: clinical characteristics of families with p53 germline mutations. J Clin Oncol. 2009; 27(8):1250-6.

4. Field M, Shanley S, Kirk J. Inherited cancer susceptibility syndromes in paediatric practice. J Paediatr Child Health. 2007; 43(4):219-29.

5. Jongmans MC, Loeffen JL, Waaders E, Hoogerbrugge PM, et al. Recognition of genetic predisposition in pediatric cancer patients: An easy-to-use selection tool. Eur J Med Genet. 2016; 59(3):116-25.

6. Li FP, Fraumeni JF Jr. Soft-tissue sarcomas, breast cancer, and other neoplasms. A familial syndrome? Ann Intern Med. 1969; 71(4):747-52.

7. Malkin D, Li FP, Strong LC, Fraumeni JF Jr, et al. Germ line p53 mutations in a familial syndrome of breast cancer, sarcomas, and other neoplasms. Science. 1990; 250(4985):1233-8.

8. Giacomazzi CR, Giacomazzi J, Netto CB, Santos-Silva P, et al. Pediatric cancer and Li-Fraumeni/Li-Fraumeni-like syndromes: a review for the pediatrician. Rev Assoc Med Bras (1992). 2015; 61(3):282-9.

9. Chompret A, Brugières L, Ronsin M, Gardes M, et al. P53 germline mutations in childhood cancers and cancer risk for carrier individuals. Br J Cancer. 2000; 82(12):1932-7.

10. Hwang SJ, Lozano G, Amos CI, Strong LC. Germline p53 mutations in a cohort with childhood sarcoma: sex differences in cancer risk. Am J Hum Genet. 2003; 72(4):975-83.

11. Hisada M, GarberJE, Fung CY, FraumeniJFJr, et al. Multiple primary cancers in families with Li-Fraumeni syndrome. $J$ Natl Cancer Inst. 1998; 90(8):606-11.

12. Valdez JM, Nichols KE, Kesserwan C. Li-Fraumeni syndrome: a paradigm for the understanding of hereditary cancer predisposition. Br J Haematol. 2017; 176(4):539-52.

13. Ognjanovic S, Olivier M, Bergemann TL, Hainaut P. Sarcomas in TP53 germline mutation carriers: a review of the IARC TP53 database. Cancer. 2012; 118(5):1387-96.

14. Guidi M, Giunti L, Lucchesi M, Scoccianti S, et al. Brain tumors in Li-Fraumeni syndrome: a commentary and case of a gliosarcoma patient. Future Oncol. 2017; 13(1):9-12.

15. Kamihara J, Rana HQ, Garber JE. Germline TP53 mutations and the changing landscape of Li-Fraumeni syndrome. Hum Mutat. 2014; 35(6):654-62.

16. Birch JM, Hartley AL, Tricker KJ, Prosser J, et al. Prevalence and diversity of constitutional mutations in the p53 gene among 21 Li-Fraumeni families. Cancer Res. 1994; 54(5):1298-304.

17. Eeles RA. Germline mutations in the TP53 gene. Cancer Surv. 1995; 25:101-24.

18. Chompret A, Abel A, Stoppa-Lyonnet D, Brugiéres L, et al. Sensitivity and predictive value of criteria for $\mathrm{p} 53$ germline mutation screening. J Med Genet. 2001; 38(1):43-7.

19. Sorrell AD, Espenschied CR, Culver JO, Weitzel JN. Tumor protein p53 (TP53) testing and Li-Fraumeni syndrome: current status of clinical applications and future directions. Mol Diagn Ther. 2013; 17(1):31-47.

20. Li FP, Fraumeni JF Jr, Mulvihill JJ, Blattner WA, et al. A cancer family syndrome in twenty-four kindreds. Cancer Res. 1988; 48(18):5358-62.

21. Bougeard G, Sesboüé R, Baert-Desurmont S, Vasseur S, et al. Molecular basis of the Li-Fraumeni syndrome: an update from the French LFS families. J Med Genet. 2008; 45(8):535-8.

22. Alonso Sánchez Á, Grupo de Trabajo en Cáncer Hereditario de la Sociedad Española de Oncología Médica. Guía de manejo del Síndrome de Li Fraumeni. Guías Clínicas SEOM; 2006. [Accessed on: July 28 ${ }^{\text {th }}, 2020$ ]. Available 
at: https:/ / seom.org/seomcms/images/ stories/ recursos / sociosyprofs / documentacion/socios/2006/ sindromeLiFraimeni/guiaSindromeLiFraimeni.pdf.

23. Malkin D. Li-Fraumeni Syndrome. Genes Cancer. 2011; 2(4):475-84.

24. Olivier M, Goldgar DE, Sodha N, Ohgaki H, et al. LiFraumeni and related syndromes: correlation between tumor type, family structure, and TP53 genotype. Cancer Res. 2003; 63(20):6643-50.

25. Ribeiro RC, Sandrini F, Figueiredo B, Zambetti GP, et al. An inherited p53 mutation that contributes in a tissue-specific manner to pediatric adrenal cortical carcinoma. Proc Natl Acad Sci U S A. 2001; 98(16):9330-5.

26. Bougeard G, Brugières L, Chompret A, Gesta P, et al. Screening for TP53 rearrangements in families with the Li-Fraumeni syndrome reveals a complete deletion of the TP53 gene. Oncogene. 2003; 22(6):840-6.

27. Bougeard G, Baert-Desurmont S, Tournier I, Vasseur S, et al. Impact of the MDM2 SNP309 and p53 Arg72Pro polymorphism on age of tumour onset in Li-Fraumeni syndrome. J Med Genet. 2006; 43(6):531-3.

28. Vahteristo P, Tamminen A, Karvinen P, Eerola H, et al. p53, CHK2, and CHK1 genes in Finnish families with Li-
Fraumeni syndrome: further evidence of $\mathrm{CHK} 2$ in inherited cancer predisposition. Cancer Res. 2001; 61(15):5718-22.

29. Daly MB, Pilarski R, Yurgelun MB, Berry M, et al. NCCN guidelines. Genetic/familial high-risk assessment: breast, ovarian and pancreatic. Version 1.2020. [Accessed in: December 2019]. Available at: https://www.nccn.org/ store/login/login.aspx? Return URL=https: / / www.nccn. org/professionals/physician_gls/pdf/genetics_bop.pdf.

30. Villani A, Shore A, Wasserman JD, Stephens D, et al. Biochemical and imaging surveillance in germline TP53 mutation carriers with Li-Fraumeni syndrome: 11 year follow-up of a prospective observational study. Lancet Oncol. 2016; 17(9):1295-305.

31. Kratz CP, Achatz MI, Brugières L, Frebourg T, et al. Cancer Screening Recommendations for Individuals with LiFraumeni Syndrome. Clin Cancer Res. 2017; 23(11):e38-45.

32. Kesserwan C, Friedman Ross L, Bradbury AR, Nichols KE. The Advantages and Challenges of Testing Children for Heritable Predisposition to Cancer. Am Soc Clin Oncol Educ Book. 2016; 35:251-69.

33. Brozou T, Taeubner J, Velleuer E, Dugas M, et al. Correction to: Genetic predisposition in children with cancer-affected families' acceptance of Trio-WES. Eur J Pediatr. 2018; 177(1):61. 